\title{
DESIGN OF ACTUATING ELEMENTS MADE OF SHAPE MEMORY ALLOYS
}

\author{
P. SCHMIDT-MENDE and H.-G. REISS \\ Krupp Industrietechnik Gmbh, Systems engineering division, D-4300 Essen 1, Germany
}

\begin{abstract}
Actuating elements made of shape memory alloys can be used in many sectors of industry. Examples include aerospace, auto manufacture, household appliances, medical equipment, heating, ventilation and air conditioning, fire protection, electrical equipment and model construction. Requirements to be taken into account for the selection of the suitable alloy, the component design and the effect stability for a particular application are explained.
\end{abstract}

Design begins with selection of a suitable alloy. Important requirements to be considered include transformation temperature, size of memory effect, hysteresis wiath, number of cycles, material strength, corrosion resistance and not least price (Fig. 1).

The most important memory alloys used today are nickel-titanium and copper-aluminium-zinc alloys. They offer high work per unit volume, complete work performance in a small temperature range, the capability of performing different types of motion (tension, compression, bending, torsion) and thus wide scope for component design.

Component design is influenced by the forces and paths required, the speed of transformation and the possibility of heating (Fig. 2). often the design scope is limited by available space. The materials can be formed, machined and welded, resulting in a wide range of possibilities of tailoring the component to the requirements of the application. By using suitable components, e.g. in the form of tension wires, torsion wires or spring elements, specially tailored force effects can be produced, maintained and cancelled out again. 
The number of cycles required determines the requirements made on effect stability, which is dependent not only on the alloy but also on its pretreatment, the forces acting and the ambient temperature (Fig. 3).

For application requiring high numbers of cycles, nickel-titanium alloys are most suitable. As a rule mechanical stresses should not exceed $130 \mathrm{~N} / \mathrm{mm}^{2}$ when nickel-titanium components are used. The ambient temperature should not be more than $100{ }^{\circ} \mathrm{C}$ higher than the $A_{S}$-temperature. In addition, a restoring force of around $25 \%$ of the maximum force to be exerted by the nickel-titanium component should be provided.

Provided the component is properly designed, the probability of memory component failure is extremely low. However, this calls for very close cooperation between user and manufacturer.

In selecting a suitable component the method of heat transfer plays an important role (Fig. 4). The speed of shape change is determined by the heating and cooling rate of the component. It is preferable for the memory component to be surrounded by a liquid or gaseous medium, heating of which will cause the component to change shape and do the required work. In such a case the component combines the functions of a sensor and an actuator. Ohmic heat in a currentcarrying component can also be used to trigger the meomory effect. Possible contact heating methods include resistance heating wires either braided or embedded in silicone rubber, sheated heating conductors an heating foils. The use of PTC thermistors offers the advantage of temperature limitation and thus protection against overheating.

When estimating and assessing the costs of using memory components it is necessary to consider overall system costs, i.e. the cost of the memory component (as a function of quantity), plus costs for heat, force coupling, housing and assembly. In terms of the memory component alone tension wire offers the best price-performance ratio. followed by torsion wire, compression springs, sheet metal, tubing and special shapes. 
For a preliminary estimate of forces, paths, moments and angles

the following formulas can be used.

\section{Tension wire}

Tensile force $F_{D}=A \cdot \sigma[N] \quad$ Path $S=I \cdot \epsilon_{M}[\mathrm{~mm}]$

\section{Torsion wire (straight)}

Moment $M_{t}=\frac{\pi \cdot d^{3} \cdot \tau}{16}[\mathrm{Nmm}]$ Torsion angle $\varphi=\frac{2 \cdot L \cdot y_{M}}{d}$ [degree]

\section{Helical spring}

Spring force $F_{S}=\frac{\pi \cdot d^{3} \cdot \tau}{8 D_{m}}[N]$ spring path $f=\frac{4 \pi r_{m}^{2} \cdot i \cdot Y_{M}}{[m m]}$ where

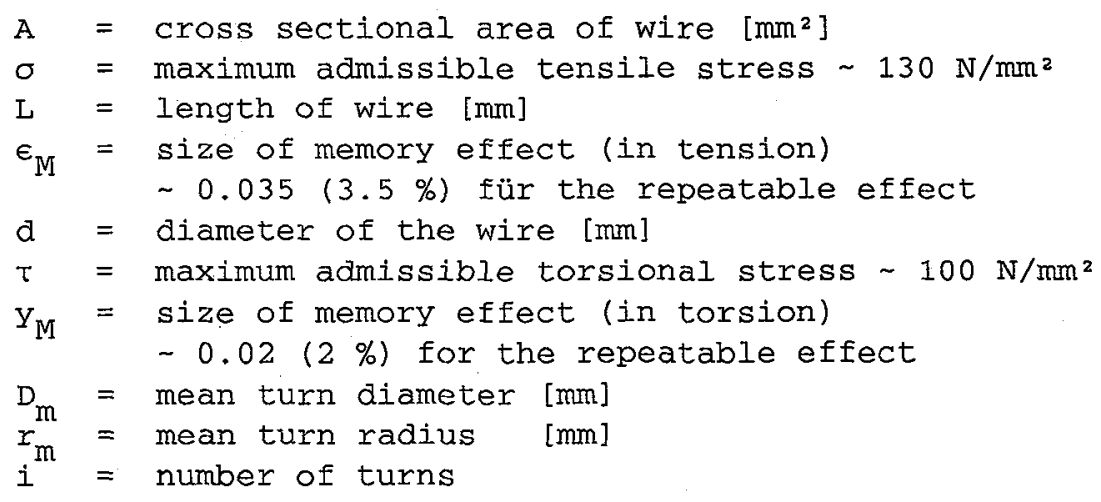

Fig. 5 shows characteristic data for thin wires stressed in tension.

In a simple example Fig. 6 shows different design possibilities for an actuator with force, path and heating given. If there are other givens, e.g. space or transformation speed, the designer will be further limited in his optimization possibilities. The best solution from a technical and economic point of view arises when memory actuator and environment can be matched to one another, i.e. when the memory element is integrated in the product at an early stage of the development process. 


\section{FACTORS WITH A BEARING ON CHOICE OF ALLOY}

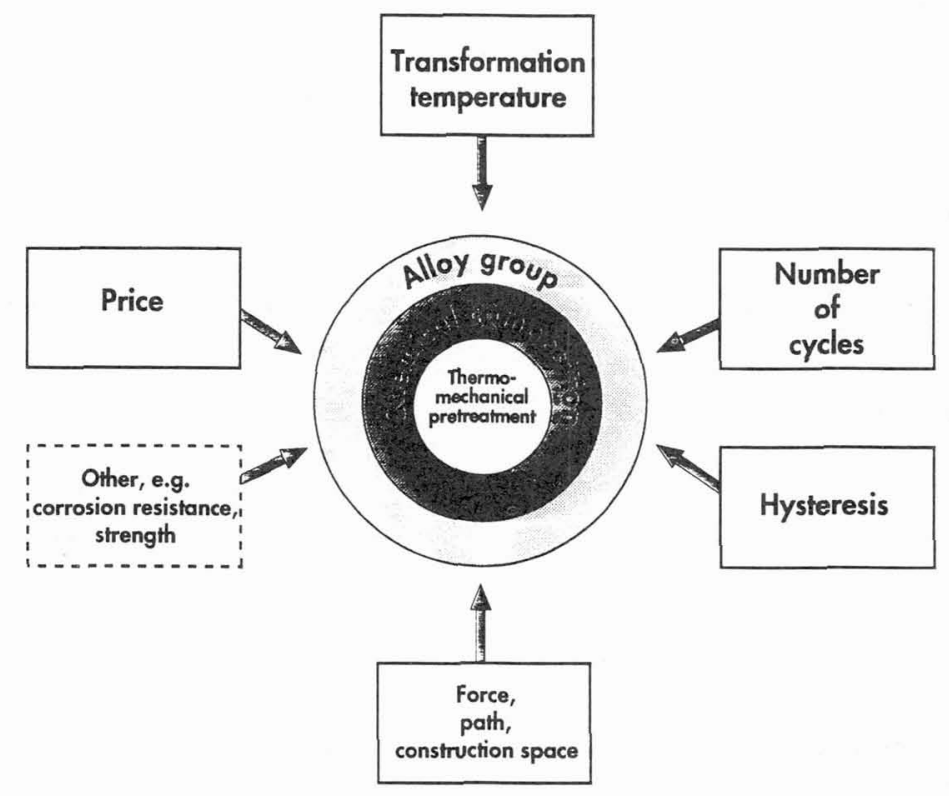

Fig. 1

\section{FACTORS WITH A BEARING ON COMPONENI SHAPE}

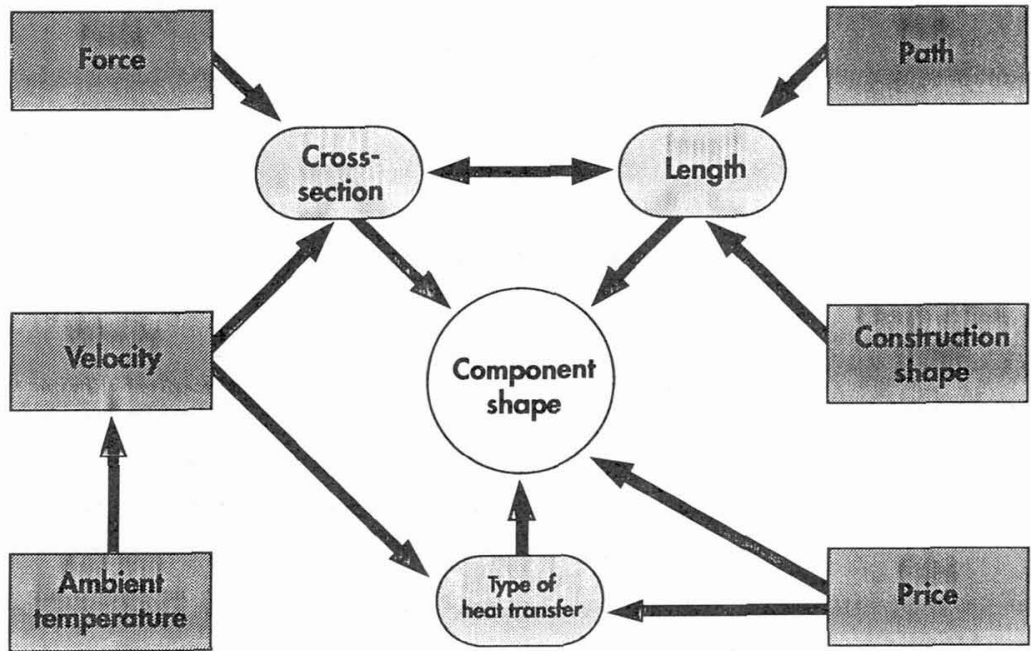

Fig. 2 
FACTORS WITH A BEARING ON LONG-TIME STABILITY

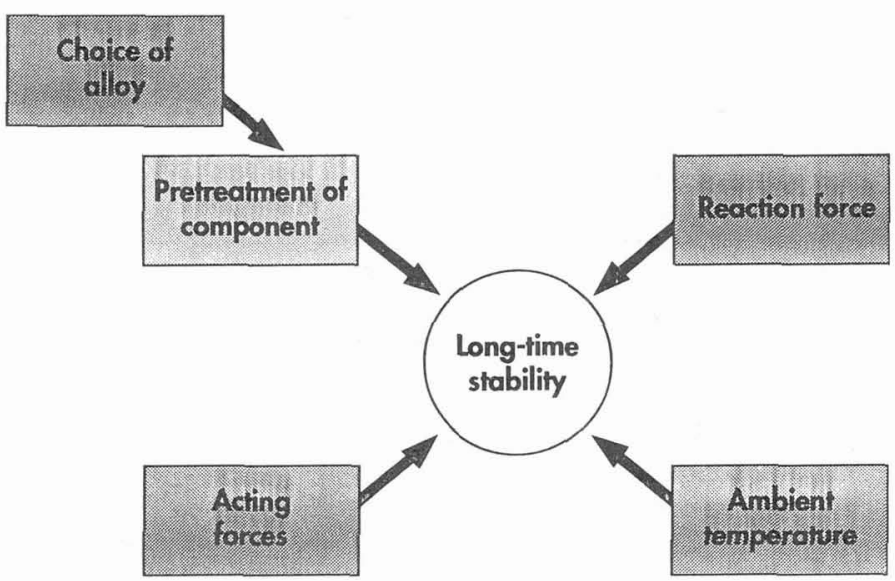

Fig. 3

\section{HEATING POSSIBILITIES FOR VARIOUS CONSTRUCTIONAL SHAPES}

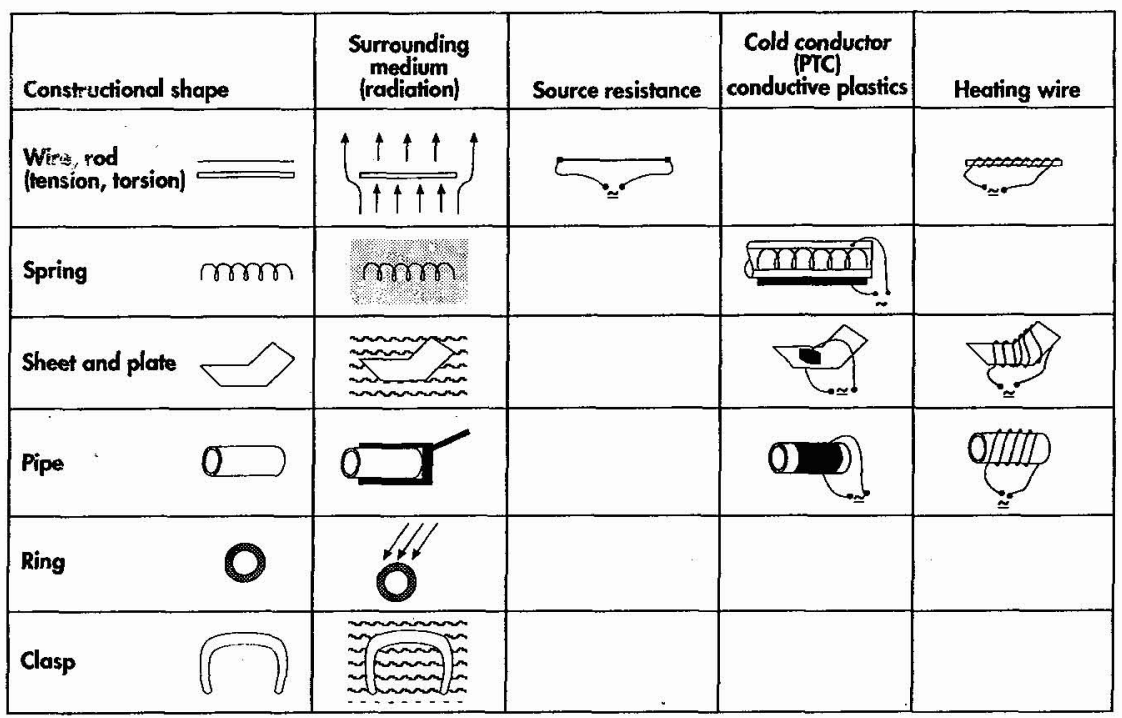


Memory - 'tension wire' of NiTiCu

Heating by ohmic resistance

Transformation temperature $A_{S}$ approx. $65^{\circ} \mathrm{C}$

\begin{tabular}{|c|c|c|}
\hline Wire Diameter & $0.12 \mathrm{~mm}$ & $0,20 \mathrm{~mm}$ \\
\hline $\begin{array}{l}\text { Memory effect (shortening) } \\
\text { on heating to } 95^{\circ} \mathrm{C}\end{array}$ & $3.5 \%$ & $3.5 \%$ \\
\hline Tensile force on heating & $1.4 \mathrm{~N}$ & $3.7 \mathrm{~N}$ \\
\hline Minimum restoring force on cooling & $0.4 \mathrm{~N}$ & $1.1 \mathrm{~N}$ \\
\hline $\begin{array}{ll}\text { Spezific ohmic resistance } & \text { at } 20^{\circ} \mathrm{C} \\
& \text { at } 95^{\circ} \mathrm{C}\end{array}$ & 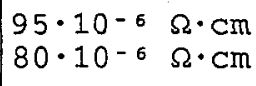 & $\begin{array}{ll}95 \cdot 10^{-6} & \Omega \cdot \mathrm{cm} \\
80 \cdot 10^{-6} & \Omega \cdot \mathrm{Cm}\end{array}$ \\
\hline $\begin{array}{ll}\text { Ohmic resistance } & \text { at } 20^{\circ} \mathrm{C} \\
& \text { at } 95^{\circ} \mathrm{C}\end{array}$ & $\begin{array}{l}84.0 \Omega / \mathrm{m} \\
66.5 \Omega / \mathrm{m}\end{array}$ & $\begin{array}{l}30.0 \Omega / m \\
23.4 \Omega / m\end{array}$ \\
\hline Max. current capacity, long-term & $250 \mathrm{~mA}$ & $470 \mathrm{~mA}$ \\
\hline $\begin{array}{l}\text { Heating voltage per m wire } \\
\text { length, long-term }\end{array}$ & $16.6 \mathrm{~V}$ & $11.0 \mathrm{~V}$ \\
\hline $\begin{array}{l}\text { Heating time with above voltage } \\
\text { and current }\end{array}$ & $3 \mathrm{sec}$. & $7 \mathrm{sec}$. \\
\hline cooling time in air at room temperature & $4.5 \mathrm{sec}$. & 7 sec. \\
\hline
\end{tabular}

Fig. 5

\section{Design example}

Given: Actuator for function 'Open - Close'; Force $3.5 \mathrm{~N}$;

Path: $10 \mathrm{~mm}$; heating: surrounding medium; alloy: Niti; $A_{S}: \approx 65{ }^{\circ} \mathrm{C}$

\begin{tabular}{|l|c|c|c|}
\hline \multicolumn{1}{|c|}{ Design } & $\begin{array}{c}\text { Tension wire } \\
\text { I }\end{array}$ & $\begin{array}{c}\text { Tension wire } \\
\text { II }\end{array}$ & Spring \\
\hline Diameter & $0.2 \mathrm{~mm}$ & $0.4 \mathrm{~mm}$ & $6 \mathrm{~mm}$ \\
\hline Length & $150 \mathrm{~mm}$ & $40 \mathrm{~mm}$ & $\begin{array}{c}\text { BIock length } \\
10 \mathrm{~mm}\end{array}$ \\
\hline Restraint & End sleeves & End sleeves & - \\
\hline Restoring spring & $1 \mathrm{~N}$ & $4 \mathrm{~N}$ & $1 \mathrm{~N}$ \\
\hline Leverage & - & $1: 4$ & - \\
\hline Space & $5 \cdot 5 \cdot 160 \mathrm{~mm}$ & $5 \cdot 5 \cdot 50 \mathrm{~mm}$ & $6 \cdot 6 \cdot 10 \mathrm{~mm}$ \\
\hline Response speed & $7 \mathrm{~s}$ heat & $\begin{array}{c}18 \mathrm{~s} \mathrm{heat} \\
\mathrm{s} \text { cool }\end{array}$ & $\begin{array}{c}20 \mathrm{~s} \text { heat } \\
25 \mathrm{~s} \text { cool }\end{array}$ \\
\hline $\begin{array}{l}\text { Prices approx. } \\
\text { Memory element }\end{array}$ & DM 2.50 & DM 0.80 & DM 2.50 \\
\hline Peripheral costs & DM 1.80 & DM 3.70 & DM 1.50 \\
\hline Total Price & DM 4.30 & DM 4.50 & DM 4.00 \\
\hline
\end{tabular}

Fig. 6 